\title{
PENGARUH KUALITAS LAYANAN TERHADAP LOYALITAS KONSUMEN MELALUI VARIABEL INTERVENING KEPUASAN KONSUMEN PADA WARUNG KELONTONG DI KECAMATAN BANJARMASIN TIMUR
}

\author{
Fanlia Prima Jaya ${ }^{1 *}$ dan Gusti Suryasari $\mathrm{R}^{2^{* *}}$
}

Program Studi Manajemen, Sekolah Tinggi Ilmu Manajemen Indonesia Banjarmasin

\begin{abstract}
, type of research is explanatory research that aims to explain the causal relationship between variables through hypothesis testing and is also a conclusive research. The population of this study was overall Consumers who use the Convenience Store in Kecamatan BanjarmasinTimur, that as many as 118.429 people. The results of this study indicate that the results of validity and reliability of all the variables are significantly related and reliable. Classic assumption test consisting of Multicollinearity test, test heterocedastity, Autokolerasi test, normality test showed no irregularities. After linear regression analysis consisting of t-test and Anova it can be concluded that the Service Quality and Consumer's Satisfaction as intervening simultaneously significant effect on Consumer's Loyalty at Convenience Store in Kecamatan BanjarmasinTimur, The size of the effect can be seen from the coefficient terminated or $\mathrm{R}^{2}=0.297$.
\end{abstract}

Keywords :Service Quality, Consumer's Satisfaction, Consumer's Loyalty.

Abstrak, Jenis penelitian yang dilakukan adalah penelitian penjelasan yang bertujuan untuk menjelaskan hubungan kausal antar variabel melalui pengujian hipotesis dan juga merupakan penelitian konklusif. Populasi penelitian ini ialah keseluruhan Konsumen yang menggunakan Warung Kelontong di Kecamatan Banjarmasin Timur yakni sebanyak 118.429 orang. Hasil penelitian ini menunjukkan bahwa hasil uji validitas dan reliabilitas semua variabel secara signifikan berhubungan dan reliable. Uji asumsi klasik yang terdiri dari Uji Multikolinearitas, Uji Heterokedastisitas, Uji Autokolerasi, Uji Normalitas menunjukkan tidak ada penyimpangan.Setelah dilakukan analisis regresi linear yang terdiri dari uji-t dan Anova maka dapat disimpulkan bahwa Kualitas Layanan(Service Quality) dan Kepuasan Konsumen(Consumer's Satisfaction) sebagai intervening secara simultan berpengaruh signifikan terhadap LoyalitasKonsumen(Consumer's Loyalty)pada warung Kelontong di Kecamatan Banjarmasin Timur. Adapun besarnya pengaruh tersebut dapat diketahui dari koefesien diterminasi atau $\mathrm{R}^{2}=0,297$.

Kata Kunci : Kualitas Layanan(Service Quality), Kepuasan Konsumen(Consumer's Satisfaction), LoyalitasKonsumen(Consumer's Loyalty). 


\section{Pendahuluan}

Usaha Kecil Menengah di Banjarmasin Timur sekarang ini cukup berkembang dengan pesat, hal ini dapat dilihat dari jumlah permintaan akan barang serta jasa yang semakin meningkat. Masyarakat dengan kemampuannya mempunyai keinginan untuk memuaskan kebutuhannya terhadap alat pemuas kebutuhan yaitu barang dan jasa. Oleh karena itu, di Banjarmasin Timur banyak sekali dijumpai Usaha Kecil Menengah seperti Warung Kelontong yang menjual aneka ragam barang kebutuhan keperluan masyarakat.Warung kelontongan ini merupakan suatu istilah dari masyarakat terhadap usaha retail yang banyak sekali di jumpai di Indonesia, WarungKelontongadalah toko yang menjual segala macam keperluan sehari hari, mulai dari peralatan mandi, peralatan makan, peralatan dapur, peralatan tulis sampai makanan ringan, lokasinya mudah di jangkau karena berdekatan sekali dengan pemukiman.

Dengan masuknya bisnis retail yaitu dalam bentuk minimarket modern di Banjarmasin terutama dengan sistem waralaba, ini akan menjadi persaingan antar retail di Banjarmasin baik Warung Kelontongyang dimiliki oleh perorangan maupun Minimarket modern dengan system waralaba yang dimiliki oleh kelompok. Hal tersebut juga menyebabkan Masyarakat mempunyai banyak alternative pilihan, apa lagi yang menyangkut masalah kecerdasan penggunaan uang (financial quotion). Warung kelontong di tuntut untuk menerapkan Kualitas Layanan (Service Quality) yang dapat dijadikan sarana dalam strategi memenangkan persaingan antar retail. Bersaing dalam meningkatkan pelayanan dan image yang ada, baik dengan menyajikan tempat dan nuansa yang nyaman harga terjangkau oleh kalangan menengah ke bawah, dan kesemuanya itu akan lebih ditunjang dengan adanya Kualitas Pelayanan (Service Quality) yang baik dan maksimal dari pengelola Warung kelontong di BanjarmasinTimur.

Penelitian ini berusaha mengukur Loyalitas Konsumen (Consumer's Loyalty) dan Kepuasan Konsumen (Consumer's Satisfaction) terhadap Warung kelontong melalui variabel Kualitas Layanan (Service Quality)Dengan menggunakan konsep dasar American Customer Satisfaction Index (ACSI) yang dikembangkan oleh Fornell, et al. dalam Terblanche (2006), di mana konsep ini adalah sistem pengukuran pelanggan/ konsumen untuk mengevaluasi dan meningkatkan kinerja dari perusahaan, industri, sektor ekonomi dan ekonomi nasionalnamun, konsep dalam Penelitian ini berbeda dengan konsep ACSI dalamhal Kepuasan Konsumen (Consumer's Satisfaction), dimana kepuasan konsumen dalam konsep ini dipengaruhi oleh Kualitas Layanan (Service Quality).

\section{Metode Penelitian}

Penelitian ini mengarah ke metode "cross sectional" untuk melakukan penjelasan keadaan saat itu, sehingga dari data yang diperoleh dapat menjelaskan ada tidaknya hubungan kausal antar variabel. Penelitian ini juga disebut penelitian penjelasan (explanatory research)karena tujuannya adalah untuk menjelaskan hubungan kausal antara variabel melalui pengujian hipotesis dan juga merupakan penelitian konklusif karena memenuhi karakteristik sebagai berikut (Malhotra, 2004): (1) Tujuannya adalah untuk menguji hipotesis mengenai hubungan antara variabel-variabel yang diteliti; (2) Informasi yang diperlukan didefinisikan dengan jelas; (3) Proses penelitian formal dan terstruktur; (4) Menggunakan sampel yang relatif besar dan representatif; dan (5) Analisis data menggunakan teknik kuantitatif. Berdasarkan hasil kajian dan analisis data maka penelitian ini termasuk dalam kategori penelitian sebab akibat (causal research). Penelitian sebab akibat adalah penelitian yang mengidentifikasi hubungan sebab akibat antara berbagai 
variabel.Adapun metode yang digunakan ialah Explanatory survey method (suatu metode penelitian survey yang bertujuan menguji hipotesis. Pengertian metode survey ini dibatasi pada pengertian survey, di mana informasi dikumpulkan dari sebagian populasi.

Populasi penelitian ini ialah keseluruhan pelanggan yang menggunakan Warung Kelontong di Kecamatan Banjarmasin Timur yakni sebanyak 118.429 orang dan diambil sampel berdasarkan hasil perhitungan dengan formula Slovin, besarnya sampel responden Pelanggan yang menggunakan Warung Kelontong di Kecamatan Banjarmasin Timur minimal sebanyak 99,91 orang atau dibulatkan menjadi 100 orang yang menggunakan Toko Kelontong di Kecamatan Banjarmasin Timur yangtersebardi 9 (Sembilan) Kelurahan di Kecamatan Banjarmasin Timur diketahui secara proporsional.

\section{Kerangka Konseptual dan Hipotesis}

Kerangka Pemikiran yang mendasari konseptual dalam Penelitian ini adalah konsep kepuasan (American Customer Satisfaction Index) dari Fornell, et al. dalam Terblanche (2006), dan SERVQUAL dari Tjiptono (2005:262). Hubungan kausal yang dibangun dalam thesis ini terdiri dari pengaruh Kualitas Layanan (Service Quality) terhadap tingkat Kepuasan Konsumen (Consumer's Satisfaction) dan Loyalitas Konsumen (Consumer's Loyalty).

Faktor yang mempengaruhi Kepuasan dan Loyalitas adalah Kualitas Layanan (Service Quality) dimana ini merupakan evaluasi terhadap produk dan pelayanan berdasarkan pengalaman konsumsi yang terbaru atau terakhir, dan diharapkan mempunyai dampak langsung dan positif pada kepuasan.

Sesuai dengan pendapat Johnson, et al (2001) dalam exit-voice theory mengatakan bahwa konsekuensi dari meningkatnya Kepuasan Konsumen (Consumer's Satisfaction) adalah berkurangnya komplain Konsumen dan meningkatnya loyalitas. Dalam penelitian ini tidak memasukkan variabel Consumer's Complain seperti yang terdapat pada konsep ACSI karena menurut pendapat peneliti, untuk Konsumen yang datang berkunjung ke Toko Kelontong dan merasa tidak puas maka mereka tidak akan melakukan komplain atau mereka akan berpindah kepada penyedia jasa lainnya, hal ini juga di dukung dengan beberapa temuan yang menyatakan bahwa komplain untuk beberapa industri penyedia jasa tidak mempunyai pengaruh signifikan terhadap loyalitas (O'Loughlin \& Coenders, 2002; Johnson, dkk., 2001; Fornel, dkk., 1996).

Hasil dari penelitian ini nantinya dari Kualitas Layanan (Service Quality) akan mempengaruhi Kepuasan Konsumen (Consumer's Satisfaction), di mana apabila konsumen merasa puas maka image mereka terhadap Toko Kelontong dalam bentuk perorangan di Banjarmasin Timur ini akan positif dan juga akan meningkatkan Loyalias Konsumen (Consumer's Loyalty). Menurut Johnson dkk., (2001:231) mengatakan bahwa data rata-rata kepuasan pelanggan yang berupa harapan sebelum pembelian itu dikumpulkan dari pengalaman setelah melakukan pembelian, atau dengan kata lain adalah mengukur kepuasan. Dan menurut Menurut Liu (2005) terdapat hubungan yang signifikan antara Kepuasan Konsumen (Consumer's Satisfaction) dengan Kualitas Layanan (Service Quality) di setiap tingkat pemisahan dari indikasi selanjutnya bahwa masing-masing sub divisi yaitu mengambil pengertian sebagai aspek penting dari kualitas pelayanan.

Berdasarkan penjelasan di atas dan pada Bab sebelumnya, maka dapat dibuat kerangka konseptual sebagai berikut :

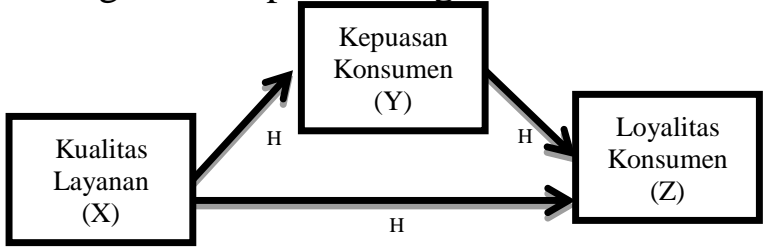


Gambar 1. KerangkaKonseptual

Sumber : 1. Teori SERVQUAL dari

Tjiptono (2005:262)

2. Teori ACSI dari Fornell, et al dalam

Terblanche (2006)

3. Studi Johnson dkk., (2001)

Berdasarkan latar belakang, rumusan masalah, tujuan penelitian dan kajian pustaka yang telah dikemukakan sebelumnya, maka yang menjadi hipotesis dalam penelitian ini adalah :

$\mathbf{H}_{1}$ : Kualitas Layanan (Service Quality) berpengaruh langsung terhadap Kepuasan Konsumen (Consumer's Satisfaction) Warung kelontong di Banjarmasin Timur.

$\mathbf{H}_{2}$ : Kualitas Layanan (Service Quality) berpengaruh langsung terhadap Loyalitas Konsumen (Consumer's Loyalty) Warung kelontong di Banjarmasin Timur.

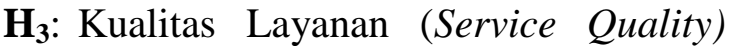
berpengaruh tidak langsung terhadap Loyalitas Konsumen (Consumer's Loyalty) melalui Variabel Intervening Kepuasan Konsumen (Consumer's Satisfaction) Warung kelontong di Banjarmasin Timur.

\section{Hasil dan Pembahasan}

Responden penelitian digambarkan secara umum dengan menyajikan karakteristik yang dapat dilihat dari demografi, yaitu: jenis kelamin, usia, dan pekerjaan. Jumlah responden yang digunakan dalam penelitian ini sebanyak 100 responden. Secara rinci, karakteristik responden dapat dilihat pada Tabel 1.

Tabel 1

Karakteristik Responden

\begin{tabular}{|c|c|c|c|c|}
\hline No. & $\begin{array}{c}\text { Karakteristik } \\
\text { Responden }\end{array}$ & Keterangan & $\begin{array}{c}\text { Jumlah } \\
\mathbf{N}\end{array}$ & $\%$ \\
\hline \multirow{3}{*}{1} & Jenis Kelamin & Laki-laki & 38 & $38 \%$ \\
\hline & & Perempuan & 62 & $62 \%$ \\
\hline & \multicolumn{2}{|l|}{ Jumlah } & & 100 \\
\hline \multirow{6}{*}{2} & \multirow[t]{5}{*}{ Jenis Pekerjaan } & PNS & 20 & $20 \%$ \\
\hline & & Wiraswasta & 25 & $25 \%$ \\
\hline & & Pelajar/ & 15 & $15 \%$ \\
\hline & & $\begin{array}{l}\text { Manasiswa } \\
\text { Ibu Rumah }\end{array}$ & 40 & $40 \%$ \\
\hline & & Tangga & 40 & \\
\hline & \multicolumn{2}{|l|}{ Jumlah } & & 100 \\
\hline
\end{tabular}

Sumber :data primer 2015

Jurnal Riset Lospirasi Mangjomen dan Kowirausabaan
Dari Tabel 1. dapat dilihat bahwa jumlah konsumen berjenis kelamin wanita merupakan mayoritas pengguna jasa warung kelontong di Banjarmasin Timur yaitu sebesar 62\%, sedangkan yang berjenis kelamin laki-laki sebagai pengguna jasa warung kelontong di Banjarmasin Timur hanya sebesar $38 \%$. Artinya pengguna jasa warung kelontong yang potensial saat ini adalah wanita, dilihat karakteristik konsumen berdasarkan jenis pekerjaan dalam menggunakan jasa warung kelontong di Banjarmasin Timur Seperti Ibu Rumah Tangga sebesar 40\%, Wiraswasta sebesar 25\%, PNS sebesar 20\%, Pelajar/ Mahasiswa sebesar 15\%, Artinya dari karakteristik konsumen berdasarkan jenis pekerjaan dalam menggunakan jasa warung kelontong di Banjarmasin Timur yang mempunyai potensi dan termotivasi memakai jasa tersebut mayoritas adalah ibu Rumah Tangga yaitu sebesar $40 \%$.

\section{Pengujian Asumsi Klasik Uji Multikolinearitas}

Uji Multikolinearitas bertujuan untuk menguji apakah pada model regresi ditemukan adanya korelasi antar variabel bebas.Jika terjadi korelasi maka dinamakan terdapat problem multikolinearitas.Model regresi yang baik seharusnya tidak terjadi korelasi diantara variabel bebas. Untuk mendeteksi adanya multikolinearitas dapat dilakukan dengan melihat nilai VIF (Variance Inflating Factor) (Singgih Santoso, 2002;112).

Pedoman suatu model yang bebas multikolinearitas analisis regresi dapat dilihat pada tabel berikut :

Tabel 2

Hasil Uji Multikolinearitas

\begin{tabular}{|c|c|c|c|}
\hline Variabel & Tolerance & VIF & Kesimpulan \\
\hline $\begin{array}{c}\text { Kualitas } \\
\text { Layanan (X) }\end{array}$ & 0,885 & 1,130 & $\begin{array}{c}\text { Tidak Terjadi } \\
\text { Multikolinearita } \\
\text { s }\end{array}$ \\
\hline $\begin{array}{c}\text { Kepuasan } \\
\text { Pelanggan } \\
\text { (Y) }\end{array}$ & 0,885 & 1,130 & $\begin{array}{c}\text { Tidak Terjadi } \\
\text { Multikolinearita } \\
\text { s }\end{array}$ \\
\hline
\end{tabular}

Sumber. Data Primer yang diolah, 2015 
Hasil Pengujian Multikolinearitas Tabel 5.27, menunjukkan nilai VIF untuk variabel $\mathrm{X}$ dan Y sebesar 1,130. Dari tabel diatas dapat diketahui bahwa nilai VIF masing - masing variabel kurang dari 5, sehingga dapat dinyatakan bahwa tidak terjadi multikolinearitas antar variabel independent dalam model regresi dan model regresi layak dipakai dan dapat dilanjutkan ke tahap pengujian selanjutnya karena memenuhi asumsi multikolinearitas.

\section{Uji Heteroskedastisitas}

Uji Heterokedastisitas bertujuan untuk menguji apakah pada model regresi terdapat ketidaksamaan varians dari residual, dari satu pengamatan ke pengamatan yang lain jika tetap maka disebut homoskedastisitas dan jika berbeda pengamatan yang lain jika tetap maka disebut regresi yang baik dan jika berbeda disebut heteroskedastisitas. Model regresi yang baik adalah homoskedestisitas atau tidak terjadi heteroskedastisitas.

Heterokedastisitas diuji dengan menggunakan uji koefesien korelasi Rank Spearman yaitu mengkorelasi antara absolut residual hasil regresi dengan semua variabel bebas. Bila signifikansi hasil korelasi lebih kecil dari 0,1 (10\%) maka persamaan regresi tersebut tidak mengandung heteroskedastisitas atau homoskedatisitas.

Pengujian

asumsi

Heteroskedastisitas dilakukan dengan menggunakan Tabel Uji dan Grafik Scatterplot. Hasil Pengujian heteroskedastisitas terlihat pada tabel 5.28 berikut ini:

Tabel 3

\section{Uji Koefesien Model Regresi}

\begin{tabular}{|c|c|c|c|c|c|c|c|}
\hline \multicolumn{8}{|c|}{ Coefficients ${ }^{a}$} \\
\hline \multirow[b]{2}{*}{ Model } & \multicolumn{2}{|c|}{$\begin{array}{c}\text { Unstandardized } \\
\text { Coefficients }\end{array}$} & \multirow{2}{*}{$\begin{array}{c}\text { Standardized } \\
\text { Coefficients } \\
\text { Beta }\end{array}$} & \multirow[b]{2}{*}{$t$} & \multirow[b]{2}{*}{ Sig. } & \multicolumn{2}{|c|}{ Collinearity Statistics } \\
\hline & $B$ & Std. Error & & & & Tolerance & VIF \\
\hline 1 (Constant) & 3.237 & .792 & & 4.088 & .000 & & \\
\hline Kualitas Layanan & .031 & .013 & .214 & 2.359 & .020 & .885 & 1.130 \\
\hline Kepuasan Konsumen & .378 & .079 & .434 & 4.797 & .000 & .885 & 1.130 \\
\hline
\end{tabular}

Dari tabel diatas dapat dinyatakan bahwa pada model regresi yang digunakan tidak terjadi heterokedastisitas.Artinya pada model regresi antara besarnya data dengan residual sehingga bila data diperbesar tidak menyebabkan residual (kesalahan) semakin besar. Hal ini dikarenakan signifikansi hasil korelasi dari masing-masing variabel lebih besar dari pada $0,1(10 \%)$.

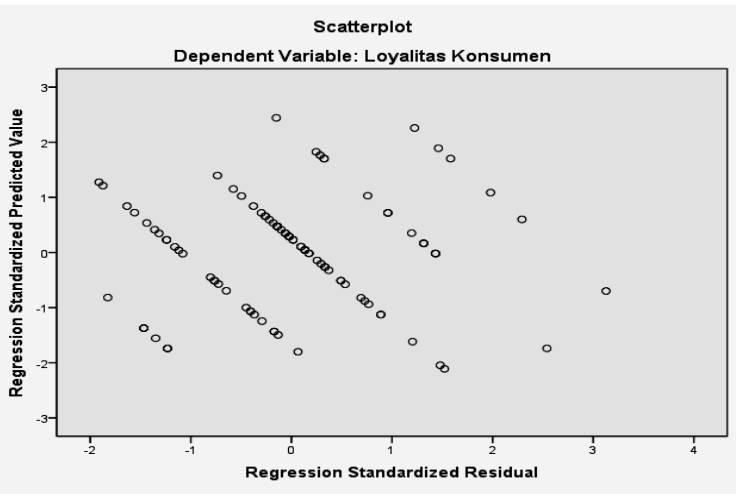

Gambar 2. Grafik Scatter Plot

Dari gambar 5.1 Grafik Scatter diatas, jelas bahwa tidak ada pola tertentu karena titik menyebar tidak beraturan diatas dan dibawah sumbu 0 pada sumbu Y. maka dapat dinyatakan tidak terjadi gejala Heteroskedastisitas atau $\mathrm{H}_{0}$ diterima. Dengan demikian pada model Regresi yang digunakan ini tidak ditemukan adanya masalah heteroskedastisitas sehingga model regresi layak dipakai karena memenuhi asumsi homoskedastisitas.

\section{Uji Autokorelasi}

Autokorelasi muncul karena observasi yang berurutan sepanjang waktu berkaitan satu sama lain (Hangke \& Reitsch, 1998;360). Tujuannya untuk menguji apakah dalam sebuah model regresi Linear berganda ada korelasi antara kesalahan pengganggu pada periode $\mathrm{t}-1$ (sebelumnya). Jika terjadi Korelasi, maka terjadi autokorelasi. Model regresi yang baik adalah bebas autokorelasi (Ghozali, 2011;95) untuk mendeteksi ada tidaknya autokorelasi, melalui metode tabel Durbin Watson yang dapat dilakukan melalui program SPSS Versi 19.00, dimana secara umum dapat diambil patokan yaitu : 
Angka $\mathrm{D}-\mathrm{W}_{\text {hitung }}<\mathrm{D}-\mathrm{W}_{\text {Tabel }}$ berarti ada autokorelasi positif

Angka $\mathrm{D}-\mathrm{W}_{\text {hitung }} \geq \mathrm{D}-\mathrm{W}_{\text {Tabel }}-2$ dan Angka $\mathrm{D}-\mathrm{W}_{\text {hitung }} \leq \mathrm{D}-\mathrm{W}_{\text {Tabel }}+2$ berarti tidak ada Autokorelasi

Angka D - W diatas +2 berarti ada autokorelasi negative.

\section{Tabel 4}

Hasil Uji Asumsi Klasik Autokorelasi Model Summary

\begin{tabular}{|l|l|r|r|r|r|}
\hline Model & R & R Square & Adjusted R R Square & Stct. Error of the Estimate & Durbin-Watson \\
\hline 1 & $.545^{\circ}$ & .297 & .283 & .795 & 2.022 \\
\hline
\end{tabular}

a. Predictors: (Constant), KepuasanKonsumen, KualitasLayanan b. Dependent Variable:

LoyalitasKonsumen

Hasil Autokorelasi pada model regresi diperoleh hasil sebagai hasil dengan melihat angka Durbin-Watson ${ }_{\text {hitung }}$ sebesar 2.022 hal ini berarti bahwa asumsi tidak terjadinya autokorelasi atau tidak terdapat masalah autokorelasi telah terpenuhi karena nilai Angka $\mathrm{D}-\mathrm{W}_{\text {hitung }} \geq \mathrm{D}-\mathrm{W}_{\text {Tabel }}-2$ dan Angka $\mathrm{D}-\mathrm{W}_{\text {hitung }} \leq \mathrm{D}-\mathrm{W}_{\text {Tabel }}+2$.

\section{Uji Normalitas}

Uji Normalitas dimaksudkan untuk mengetahui apakah residual yang diteliti berdistribusi normal atau tidak. Metode yang digunakan untuk menguji normalitas dalam penelitian ini peneliti menggunakan uji normal P-P Plot of Standardized Residual. Dari hasil pengujian Normalitas dengan metode uji normal P-P Plot of Standardized Residual, dependent Variabel :Loyalitas Pelanggan (Z) sebagaimana terlihat pada gambar 5.2 berikut ini :

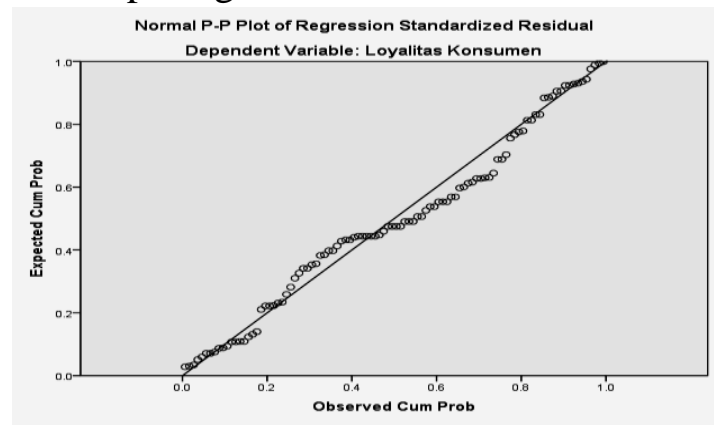

\section{Gambar 3. Grafik Sebaran Data Model Regresi}

Berdasarkan tampilan output chat diatas, deteksi normalitas data dilakukan dengan melihat penyebaran data (titik) pada sumbu diagonal dari grafik. Dari grafik diatas, terlihat titik-titik menyebar disekitar garis diagonal, serta penyebarannya mengikuti arah garis diagonal sehingga dapat dinayatakan bahwa model regresi telah memenuhi asumsi normalitas. Maka model regresi layak dipakai untuk memprediksi.

\section{Analisis Regresi Linier}

Analisis secara parsial pengaruh Kualitas Layanan terhadap Kepuasan Konsumen

Paradigma pengaruh Kualitas Layanan terhadap Kepuasan Pelanggan dapat digambarkan sebagai berikut :

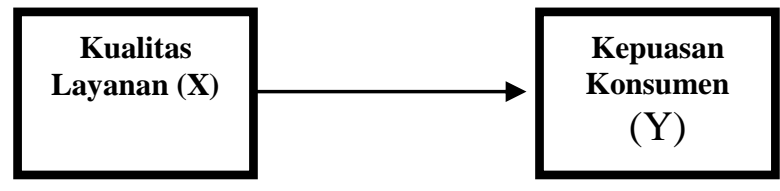

\section{Gambar 4. Konstelasi Variabel X terhadap Y}

$$
\begin{aligned}
& \mathrm{Y}=\alpha+\beta \mathrm{X}+\mathrm{e}_{\mathrm{i}} \\
& \mathrm{Y}=4.258+0,057 \mathrm{X}+\mathrm{e}_{\mathrm{i}} \\
& \mathrm{S} \quad 0,340 \\
& \mathrm{t} \quad 3,574 \\
& \mathrm{r}=0,340 \quad \mathrm{r}^{2}=0,115
\end{aligned}
$$

jika $\alpha=5 \%$ dan $\mathrm{n}=100$, maka $\mathrm{t}_{\cdot \alpha ; \mathrm{n}-1}=$ $\mathrm{t}_{0,5 ; 99}=1,660$

Dari data - data diatas diketahui bahwa elastisitas Kualitas Layanan terhadap Kepuasan Konsumen adalah sebesar 4.258, berdasarkan elastisitas tersebut diketahui bahwa setiap adanya peningkatan frekuensi Kualitas Layanan sebesar 1\%, maka akan mengakibatkan peningkatan Kepuasan Konsumen sebesar 4.258\%.Dengan memperhatikan besarnya koefesien korelasi ( $r$ ) sebesar 0,340, maka dapat dinyatakan bahwa hubungan antara Kualitas Layanan dengan Kepuasan Konsumen adalah Positif rendah, artinya semakin banyak Kualitas Layanan maka 
akan semakin meningkatkan Kepuasan Konsumen.Berdasarkan temuan diatas, bahwa thitung sebesar 3,547 dan jika dibandingkan dengan $t_{\text {tabel }}$ sebesar 1,660 dapat dinyatakan bahwa $t_{\text {hitung }}>t_{\text {tabel }}$, maka artinya pengaruhnya signifikan, sehingga dapat dinyatakan bahwa Kualitas Layanan secara positif berpengaruh signifikan terhadap Kepuasan Konsumen.Adapun besarnya pengaruh kecerdasan emosional tersebut dapat diketahui dari koefesien diterminasi $r^{2}$ sebesar 0,115 yang artinya bahwa sebesar 11,5\% Kualitas Layanan dipengaruhi oleh Kepuasan Konsumen, dan sisanya sebanyak 88,5 \% Kepuasan Konsumen dipengaruhi oleh Faktor lain.

\section{Analisis secara parsial pengaruh Kualitas Layanan terhadap Loyalitas Konsumen}

Paradigma pengaruh Kualitas Layanan terhadap Loyalitas Konsumen dapat digambarkan sebagai berikut :

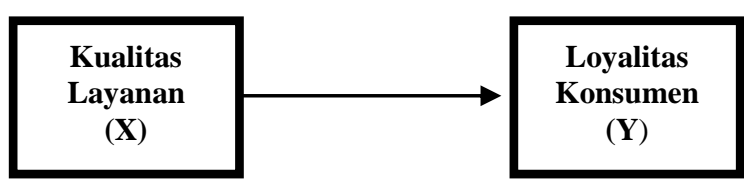

\section{Gambar 5Konstelasi Variabel X} terhadap Z

$\mathrm{Z}=\alpha+\beta \mathrm{X}+\mathrm{e}_{\mathrm{i}}$

$Z=4.848+0,053 X+e_{i}$

$\mathrm{S} \quad 0,361$

$\mathrm{t} \quad 3,831$

$\mathrm{r}=0,361 \quad \mathrm{r}^{2}=0,130$

jika $\alpha=5 \%$ dan $\mathrm{n}=100$, maka $\mathrm{t}_{\cdot \alpha ; \mathrm{n}-1}=$ $\mathrm{t}_{0,5 ; 99}=1,660$

Dari data - data diatas diketahui bahwa elastisitas Kualitas Layanan terhadap Loyalitas Konsumen adalah sebesar 4.848, berdasarkan elastisitas tersebut diketahui bahwa setiap adanya peningkatan frekuensi Kualitas Layanan sebesar $1 \%$, maka akan mengakibatkan peningkatan Loyalitas Konsumen sebesar 4.848\%.Dengan memperhatikan besarnya koefesien korelasi ( $\mathrm{r}$ ) sebesar 0,361, maka dapat dinyatakan bahwa hubungan antara Kualitas Pelayanan dengan Loyalitas Konsumen adalah Positif rendah, artinya semakin diperkuat Kualitas Layanan maka akan semakin meningkatkan Loyalitas Konsumen.Berdasarkan temuan diatas,

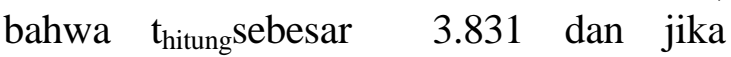
dibandingkan dengan $t_{\text {tabel }}$ sebesar 1,660 dapat dinyatakan bahwa $t_{\text {hitung }}>t_{\text {tabel }}$, maka artinya pengaruhnya signifikan, sehingga dapat dinyatakan bahwa Kualitas Layanan secara positif berpengaruh signifikan terhadap Loyalitas Konsumen.Adapun besarnya pengaruh kecerdasan emosional tersebut dapat diketahui dari koefesien diterminasi $r^{2}$ sebesar 0,130 yang artinya bahwa sebesar $13 \%$ Loyalitas Konsumen dipengaruhi oleh Kualitas Layanan, dan sisanya sebanyak 87\% Loyalitas Konsumen dipengaruhi oleh Faktor lain.

Analisis secara simultan pengaruh Kualitas Layanan terhadap Kepuasan Konsumen \& Loyalitas Konsumen

Paradigma pengaruh Kualitas Layanan terhadap Kepuasan Konsumen dan Loyalitas Konsumen dapat digambarkan sebagai berikut :

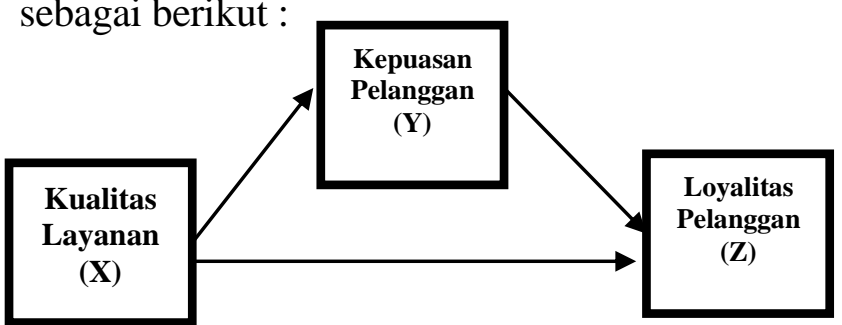

Gambar.6 Konstelasi Variabel X, Y terhadap $\mathrm{Z}$

$$
\begin{aligned}
& \mathrm{Z}=\alpha+\beta \mathrm{X}+\beta \mathrm{Y}+\mathrm{e}_{\mathrm{i}} \\
& \mathrm{Y}=3,237+0,031 \mathrm{X}+0,378 \mathrm{Y}+\mathrm{e}_{\mathrm{i}} \\
& \mathrm{S} \quad 0,214 \quad 0,434 \\
& \mathrm{t} \quad 2,359 \quad 4,797
\end{aligned}
$$

$\mathrm{R}=0,545 \quad \mathrm{R}^{2}=0,297$ jika $\alpha=5 \%$ dan $\mathrm{n}=100$, maka $\mathrm{t}_{\cdot \alpha ; \mathrm{n}-1}=$ t.0,5;99 $=1,660$

Dari data-data diatas secara simultan Kualitas Layanan dan Kepuasan Konsumen sebagai intervening diketahui besarnya koefesien korelasi ( $\mathrm{R}$ ) sebesar 0,545, maka dapat dinyatakan bahwa hubungan antara Kualitas Layanan dan Kepuasan Konsumen sebagai intervening secara simultan dengan Loyalitas 
Konsumen adalah cukup kuat positif, artinya semakin meningkat Kualitas Layanan dan Kepuasan Konsumen sebagai intervening secara simultan, maka akan semakin meningkat Loyalitas Konsumen.

Berdasarkan temuan diatas, bahwa $\mathrm{t}_{\text {hitung }}$ untuk parameter $\beta \mathrm{X}$ sebesar 2,359, $t_{\text {hitung }}$ untuk parameter $\beta$ Ysebesar $4,797^{* *}$. Kaedah keputusan dinyatakan bahwa jika $t_{\text {hitung }}>t_{\text {tabel }}$, artinya pengaruhnya signifikan, dan sebaliknya jika $t_{\text {hitung }}<t_{\text {tabel }}$ , artinya pengaruhnya tidak signifikan. Berdasarkan data diatas, diketahui bahwa $\mathrm{t}_{\text {tabel }}$ sebesar 1,660, sehingga secara parsial dapat dinyatakan bahwa Kualitas Layanan signifikan terhadap Loyalitas Konsumen, dan Kepuasan Konsumen sangat signifikan terhadap Loyalitas Konsumen.

Selanjutnya untuk mengetahui pengaruhnya secara simultan, dapat dilihat pada tabel Analisis Of Varians (ANOVA) sebagai berikut :

\section{Tabel 5}

Analisis Of Varians (ANOVA) ANOVAb

\begin{tabular}{|l|r|r|r|r|c|c|}
\hline \multicolumn{2}{|l|}{ Model } & Sum of Squares & df & Mean Square & F & Sig. \\
\hline \multirow{2}{*}{1} & Regression & 25.934 & 2 & 12.967 & 20.493 & $.000^{\mathrm{g}}$ \\
\cline { 2 - 8 } & Residual & 61.376 & 97 & .633 & & \\
\cline { 2 - 8 } & Total & 87.310 & 99 & & & \\
\hline
\end{tabular}

Dari tabel 5.30 diatas, diketahui bahwa $\mathrm{F}_{\text {hitung }}=20.493>\mathrm{F}_{0,05 ; 100-3}=3,09$ dan sig. atau $\mathrm{p}=0,000<$ dari $\alpha=5 \%$. Dengan demikian Kualitas Layanan dan Kepuasan Konsumen sebagai intervening secara simultan berpengaruh signifikan terhadap Loyalitas Konsumen. Adapun besarnya pengaruh tersebut dapat diketahui dari koefesien diterminasi atau $\mathrm{R}^{2}=0,297$ artinya 29,7 \% kualitas Layanan dan Kepuasan Konsumen sebagai intervening secara simultan berpengaruh secara signifikan terhadap Loyalitas Konsumen, dan sisanya 70,3\% Loyalitas Konsumen tersebut dipengaruhi faktor lain.

\section{Pengujian Hipotesis Model Regresi}

Berdasarkan hasil analisis model regresi Kualitas Layanan terhadap Loyalitas Pelanggan dan Kepuasan Pelanggan sebagai intervening. Hasil Pengujian Hipotesis dapat dilihat pada tabel 5.31 berikut :
Tabel 5

\section{Hasil Pengujian Hipotesis}

\begin{tabular}{|c|c|c|c|c|c|}
\hline No & Hipotesis & $r^{2}$ & $\mathrm{~T}_{\text {hiturg }}$ & $\mathrm{T}_{\text {tabel }}$ & Keterangan \\
\hline 1. & Kualitas Layanan $(\mathrm{X}) \nrightarrow$ Kepuassan Konsumen $(\mathrm{Y})$ & 0,115 & 3,574 & 1,671 & Sigifikan \\
\hline 2. & Kualitas Layaman $(X)>$ Loyalitas Konsumen $(Z)$ & 0,130 & 3,831 & 1,671 & Sigififikan \\
\hline 3. & $\begin{array}{l}\text { Kualitas Layanan }(\mathrm{X}) \rightarrow \text { Kepuasan Konsumen }(\mathrm{Y}) \rightarrow \\
\text { Loyalitas Konsumen }(\mathrm{Z})\end{array}$ & 0,297 & $\begin{array}{l}F_{\text {kitug }} \\
20,493 \\
\end{array}$ & $\begin{array}{l}F_{\text {tidid }} \\
3,09 \\
\end{array}$ & Signifikan \\
\hline
\end{tabular}

Berdasarkan tabel 5.32 diatas dapat dijelaskan hasil pengujian hipotesis sebagai berikut :

1) Hipotesis ke satu (H1) diterima, yang artinya bahwa Kualitas Layanan berpengaruh secara signifikan terhadap Kepuasan Konsumen, sebesar 11,5\% dan sisanya 85,5 \% Kepuasan Konsumen dipengaruhi oleh faktor lain.

2) Hipotesis ke dua (H2) diterima, yang artinya bahwa Kualitas Layanan berpengaruh secara signifikan terhadap Loyalitas Konsumen, sebesar $13 \%$ dan sisanya $87 \%$ Loyalitas Konsumen dipengaruhi oleh faktor lain.

3) Hipotesis ke tiga (H3) diterima, yang artinya bahwa Kualitas Layanan dan Kepuasan Konsumen sebagai intervening secara simultan berpengaruh signifikan terhadap Loyalitas Konsumen, sebesar 29,7 \% dan sisanya 70,3 \% Loyalitas Konsumen dipengaruhi oleh faktor lain.

\section{Simpulan dan Saran}

Berdasarkan pengujian hipotesis dan pembahasan hasil penelitian disimpulkan sebagaiberikut: pertama Kualitas Layanan (Service Quality) berpengaruh langsung terhadap Kepuasan Konsumen (Consumer's Satisfaction) Warung kelontong di Banjarmasin Timur, keduaKualitas Layanan (Service Quality) berpengaruh langsung terhadap Loyalitas Konsumen (Consumer's Loyalty) Warung kelontong di Banjarmasin Timur, ketigaKualitas Layanan (Service Quality) berpengaruh langsung terhadap Loyalitas Konsumen (Consumer's Loyalty) melalui 
variabel intervening Kepuasan Konsumen (Consumer's Satisfaction)Warung kelontong di Banjarmasin Timur

Berdasarkan hasil penelitian dan pembahasan, maka saran yang dapat diberikan pada pengelola Warung Kelontong di Banjarmasin Timur, pertama Pengelola Warung Kelontong di Banjarmasin Timur perlu meningkatkan lagi kebersihannnya agar dapat mempengaruhi Kepuasan Konsumen dalam melakukan kegiatan berbelanja produk pada warung kelontong, kedua Pengelola Warung Kelontong juga diharapkan dapat berani memanfaatkan bantuan dana dari lembaga keuangan agar dapat menambah modal usahanya dan juga dapat memberikan pelayanan yang lebih baik kepada konsumen, ketiga pengelola warung kelontong juga perlu mengadakan promosi seperti potongan harga, bonus pembelian, undian berhadiah dan sebagainya untuk dapat menarik perhatian konsumen, saran kepada pemerintah terkait pertama Perlu adanya kebijakan yang bisa mendukung Usaha Mikro Kecil agar dapat mengembangkan Usaha Mikro Kecil seperti Warung Kelontong yang dikelola masyarakat di Banjarmasin Timur, keduaPerlu adanya koordinasi antara lembaga keuangan dengan pemerintah terkait agar dapat membuat program pemberian fasilitas kredit yang memadai kepada Usaha Mikro Kecil seperti Warung Kelontong yang dikelola masyarakat di Banjarmasin Timur, agar Usaha Mikro Kecil seperti Warung Kelontong ini dapat berkembang dengan baik

\section{REFERENSI}

Alida Palilati. 2004. Pengaruh tingkat kepuasan terhadap loyalitas nasabah tabungan Perbankan di wilayah etnik bugis. Jurnal Analisis Pengaruh Tingkat Kepuasan. Volume 1, Nomor 2, Maret. Hal 66-67

Arikunto, Suharsimi, \& Lia Yuliana, 2008, Manajemen Pendidikan, Yogyakarta: Aditya Media \& FIP UNY.
Arikunto, Suharsimi, 2006, Prosedur Penelitian: Suatau Pendekatan Praktek, Jakarta: Rineka Cipta.

Arikunto, Suharsimi, 2007, Manajemen Penelitian, Jakarta: Rineka Cipta.

Bungin, M., Burhan, 2009, Metodologi Penelitian Kuantitatif, Kencana Prenada media Group, Surabaya.

Fornell, Johnson, Anderson, Cha, and Bryant. 1996. The American Customer Satisfaction Index: Nature, Purpose, and Findings. Journal of Marketing. Vol.60 No.7-18.

(http://findarticles.com/p/articles/mi qa5465/is_200604/ai_n21402997/, diakses 21 Mei 2011).

Garvin, David, "managing Quality", di dalam Nasution, M.N. 2001. Manajemen Alutu Terpadu (Total Qulity management). Jakarta: Ghalia Indonesia.

Ghozali, Imam, 2009. Aplikasi Analisis Multivariate Dengan Program SPSS, Edisi Keempat, Penerbit Universitas Diponegoro.

Hair, et al. 2006. Multivariate Data Analysis 6 Th ED. New Jersey : Person Education

Hanke, J. E., dan Reitsch, Arthur G. 1998. Business Forecasting. Sixth Edition. New Jersey. Prentice Hall.

Hilmawan, Made Irvan. 2011. “ Pengaruh Kualitas Layanan terhadap Loyalitas melalui Kepuasan Konsumen Studi pada Trans Sarbatiga.

http://download.portalgaruda.org/article.ph $\mathrm{p}$ ? article $=151159$ 
Jaya, Fanlia Prima. 2013. "Pengaruh Kualitas Pelayanan Terhadap Loyalitas Pelanggan Melalui Variabel Intervening Kepuasan Konsumen Pada Restaurant Ayam Bakar Wong Solo Cabang Banjarmasin. Al-Ulum Journal Voulme 63 Nomor 1.

Johnson, Michael D., Gustafsson., Anders A., Tor, Wallin L., Line C., and Jaesung. 2001. The Evolution and Future of National Customer Satisfaction Index Models. Journal of Economic Psychology. Vol. 22, 217-245.

(www.iiis.org/CDs2010/CD2010SCI /IMETI_2010/.../FA678TN.pdf, diakses 21 Mei 2011)

Kotler P., and Gary Armstrong. 2001. Principles of Marketing. Ninth Edition, Prentice Hall, Inc, USA.

Liu M.C. 2005, The Multi Dimensional and Hierarchical Structure of Perceived Quality and Customer Satisfaction. International Journal of Management, Vol. 22, No.3. Diakses 21 Mei 2001 dari ejournal.

LupiyoadiR.2001. Manajemen Pemasaran Jasa. Jakarta : PT. Salemba Empat.

Malhotra, N.K. 2004. Marketing Research: An Applied Orientation. 4th Edition. New Jersey: Pearson Education Inc.

O'Loughlin, Christina dan Coenders G. 2002. Application of the European Customer Satisfaction Index to Postal Service. Structural Equation Models Versus Partial Least Squares.

(http://www.scribd.com/doc/51285076/Mo del-Indeks-Kepuasan-Pelanggan, diakses 21 Mei 2011)

Parasuraman, A., Zeithaml, V.A dan Berry, L.L. (1994). "Reassessment of Expectations as a Comparison Standart in Measuring Service Quality: Implication for Futher Research"' Journal of Marketing,J anuary, 111:124.

Santoso, Singgih. 2012. Panduan Lengkap SPSS Versi 20. Jakarta: PT Elex Media Komputindo.

Sugiarto. 2001. Teknik Sampling. Jakarta : PT. Gramedia Pustaka Utama.

Sugiarto, dkk. 2001. Teknik Sampling. Penerbit PT Gramedia Pustaka Utama. Jakarta

Suharso P. 2009. Metode Penelitian Kuantitatif untuk Bisnis : Pendekatan Filosofi dan Praktis. Jakarta : PT. Indeks

Sukesi, 2011, Analisis Perilaku Masyarakat Petambak Garam Terhadap Hasil Usaha di Kota Pasuruan, Jurnal Mitra Ekonomi dan Manajemen Bisnis, Vol.2, No. 2, Oktober 2011, 225-244 ISSN 20871090 Fakultas Ekonomi Universitas Dr. Soetomo Surabaya Email: greenpct@yahoo.com

Supriyatmini T.S. 2005. Kualitas Pelayanan Terhadap Loyalitas Nasabah. Semarang : Universitas Negeri Semarang.

Sutisna. (2001), Perilaku Konsumen dan Komunikasi Pemasaran, Penerbit PT. Remaja Rosdakarya, Bandung, Cetakan I.

Swastha B. 2000. Azas-azas Marketing. Liberty. Yogyakarta.

Taylor, Steven. A., Celuch, Kevin, dan Goodwin Stephen, 2004, The Important of Brand Equity to Customer Loyalty, Journal of Product and Brand Management, Volume 13, Nomor 4, hal. 217-227.

Tjiptono. 2000. Strategi Pemasaran. Edisi 1. Yogyakarta: Penerbit Andi. 
Tjiptono. 2004, Pemasaran Jasa, Bayu Media Malang.

Tjiptono. 2005. Manajemen Jasa. Edisi 3.Yogyakarta : Penerbit Andi.

Tjiptono, dan Chandra G. 2003. Total Quality Mangement. Yogyakarta : Penerbit Andi.

Tjiptono, dan Chandra G,. 2005. Service, Quality \& Satisfaction. Yogyakarta : Penerbit Andi

Utomo, Priyanto Doyo, 2006, Analisis Terhadap Faktor-Faktor Yang Mempengaruhi Loyalitas Konsumen Pada Operator Telepon Seluler. Thesis: Universitas Gadjah Mada

Wijaya, Elita Mieke. 2011. "Pengaruh Kualitas Pelayanan Terhadap Loyalitas Konsumen, dengan kepuasan konsumen sebagai variable intervening Studi pada Waterpark Semawis semarang.

http://eprints.undip.ac.id/32610/1/JU $\underline{\text { RNAL.pdf }}$

Yanto, Agus Fitri. 2010. "Analisis Pengaruh Kualitas Layanan Terhadap Loyalitas Konsumen dengan Kepuasan sebagai Variabel Intervening pada Pengguna Jasa Kereta api di Kabupaten Purworejo. IPI Journal Edisi 1 Nomor 1 Maret 2010.

Yayasan Lembaga SABDA (YLSA), http://kamus.sabda.org/kamus/warun g diunduh tanggal 26 Febuari 2015 Jam 16:32 Wita 